\title{
Clustering of transcriptional profiles identifies changes to insulin signaling as an early event in a mouse model of Alzheimer's disease
}

\author{
Harriet M Jackson ${ }^{1}$, Ileana Soto ${ }^{1}$, Leah C Graham ${ }^{1,2}$, Gregory W Carter ${ }^{1}$ and Gareth R Howell ${ }^{1,2^{*}}$
}

\begin{abstract}
Background: Alzheimer's disease affects more than 35 million people worldwide but there is no known cure. Age is the strongest risk factor for Alzheimer's disease but it is not clear how age-related changes impact the disease. Here, we used a mouse model of Alzheimer's disease to identify age-specific changes that occur prior to and at the onset of traditional Alzheimer-related phenotypes including amyloid plaque formation. To identify these early events we used transcriptional profiling of mouse brains combined with computational approaches including singular value decomposition and hierarchical clustering.
\end{abstract}

Results: Our study identifies three key events in early stages of Alzheimer's disease. First, the most important drivers of Alzheimer's disease onset in these mice are age-specific changes. These include perturbations of the ribosome and oxidative phosphorylation pathways. Second, the earliest detectable disease-specific changes occur to genes commonly associated with the hypothalamic-adrenal-pituitary (HPA) axis. These include the down-regulation of genes relating to metabolism, depression and appetite. Finally, insulin signaling, in particular the down-regulation of the insulin receptor substrate 4 (Irs4) gene, may be an important event in the transition from age-related changes to Alzheimer's disease specific-changes.

Conclusion: A combination of transcriptional profiling combined with computational analyses has uncovered novel features relevant to Alzheimer's disease in a widely used mouse model and offers avenues for further exploration into early stages of $A D$.

\section{Background}

Alzheimer's disease (AD) is an age-related neurodegenerative disease characterized by selective dysfunction and loss of neurons in specific regions of the brain including the cortex and hippocampus [1-3]. The levels of neuronal dysfunction correlate with learning and memory deficits that severely impede a patient's ability to live independently. Amyloid precursor protein (APP) and its derivatives (forms of $\beta$-amyloid, $A \beta$ ) are thought to play a central role in $\mathrm{AD}$, affecting both intra- and extra-neuronal processes [4-8]. With an aging population, $\mathrm{AD}$ is on the increase and could affect more than 50 million people worldwide by $2050[9,10]$. Attempts to develop new treatments for $\mathrm{AD}$ have proven unsuccessful [11-16] which likely highlights the lack of

\footnotetext{
* Correspondence: gareth.howell@jax.org

'The Jackson Laboratory, 600 Main Street, Bar Harbor, Maine 04609, USA

${ }^{2}$ School of Medicine, Tufts University, Boston, USA
}

understanding of the disease, particularly its onset and early progression.

$\mathrm{AD}$ is commonly divided into two subtypes - early onset (or familial) and late onset (or sporadic) [17-21]. Early-onset $\mathrm{AD}$ generally presents itself before age 65 with late-onset $\mathrm{AD}$ developing later in life. Mutations identified in genes such as APP and presenilin 1 and 2 (PSEN1 and PSEN2) contribute to early onset AD [22-25]. Variations in many genes including apolipoprotein $\mathrm{E}(A P O E)$ have been associated with late-onset $\mathrm{AD}$, but their interactions to cause AD are unclear [26-28]. Key hallmarks of both types of $\mathrm{AD}$ are neurofibrillary tangles and $\mathrm{A} \beta$ plaques $[3,29,30]$. However, their appearance, particularly neurofibrillary tangles, are likely to represent stages of the disease at which neuronal dysfunction has already begun, and it may be difficult to develop treatments that effectively target events from these stages onwards. Therefore it is essential to better understand the earlier stages of the disease that 
precede the onset of neurofibrillary tangles and plaques. These earlier stages are likely to extend over many decades in humans and targeting them provides the greatest opportunity for therapeutic intervention.

Identifying the onset and early progression of any complex age-related disease using humans or non-human primates alone is particularly challenging. Therefore, an increased understanding of the molecular and cellular processes occurring during early disease stages requires the use of animal models. The mouse has been widely used to investigate sub-phenotypes of $\mathrm{AD}$ such as amyloidosis [31-33], reactive astrogliosis [34,35] and neuroinflammation [36-38]. However, the mouse models have not been used to identify the molecular events that occur very early during disease, prior to or at the onset of the traditional hallmarks of AD. To identify these early molecular changes we performed clustering of transcriptional profiling data generated from mouse brains that showed a range in disease severity from no to early signs of AD. We had previously applied transcript clustering to identify early molecular stages in a mouse model of glaucoma [39-41]. In this present study, we used the $A P P^{\text {swe }} P \operatorname{Psen} 1^{\text {deg }}$ mouse model of $\mathrm{AD}$, which is reported to develop plaques from 6 months of age [2,42-44]. Transcript clustering identifies age-specific changes as critical for the onset and early progression of $\mathrm{AD}$ in these mice. Moreover, we used clustering of transcriptional profiles to identify changes to insulin signaling as an important early event in AD.

\section{Methods}

\section{Mouse strains and husbandry} C57BL/6J.APP ${ }^{\text {swe }}$ Psen $^{\text {de9 }}$ mice (JR005864, [2], herein referred to as $B 6 . A P B^{T g}$ ) were obtained from The Jackson Laboratory and maintained in 14/10-hour light/dark cycle. All experiments were approved by the Animal Care and Use Committee at The Jackson Laboratory. To generate experimental mice, B6.APB ${ }^{T g /+}$ mice were mated to C57BL/ $6 \mathrm{~J}$ (B6) mice to generate AD and wild-type (WT) cohorts. To minimize gene expression variation between mice, all mice in experimental cohorts were bred in the same mouse room, were aged together (to the extent possible) and only females were assessed. Mice from 2-12 months old were used in this study.

\section{Tissue harvesting, RNA isolation and sequencing Tissue harvesting}

A total of 22 mice were selected for transcriptional profiling: 8 at 4 months (4 WT, $4 \mathrm{AD}$ ), 7 at 5 months (all $\mathrm{AD}$ ) and 7 at 6 months ( $3 \mathrm{WT}, 4 \mathrm{AD}$ ). At the above ages, mice were sacrificed and the brain dissected free from the skull. The left hemisphere was snap frozen for preservation of RNA for gene expression studies. The right hemisphere was fixed in $4 \%$ paraformaldehyde overnight at $4{ }^{\circ} \mathrm{C}$ and stored in $1 \times$ Phosphate-buffered solution (PBS) at $4^{\circ} \mathrm{C}$ for future use.

\section{RNA isolation and library preparation}

RNA was extracted from the left hemisphere of each brain using Trizol (Invitrogen, CA). mRNA was purified from total RNA using biotin-tagged poly dT oligonucleotides and streptavidin-coated magnetic beads followed by QC using an Agilent Technologies 2100 Bioanalyzer. The mRNA was then fragmented, and double-stranded cDNA generated by random priming. The ends of the fragmented DNA were converted into phosphorylated blunt ends. An 'A' base was added to the 3' ends. Illumina'specific adaptors were ligated to the DNA fragments. Using magnetic bead technology, the ligated fragments were size-selected and then a final PCR was performed to enrich the adapter-modified DNA fragments, since only the DNA fragments with adaptors at both ends will amplify.

\section{High-throughput sequencing}

To minimize sequencing batch effects, all 22 samples were barcoded and combined, and sequenced across six lanes on an Illumina HiSeq 2000 using standard conditions to generate $100 \mathrm{bp}$ paired end sequences. A minimum of 29 million paired end reads were generated for each sample.

\section{RNA Sequence analysis and clustering}

Analysis of sequence was performed in a private instance of the publicly available Galaxy (https://main.g2.bx.psu.edu/).

\section{Quality control of sequence}

Sequence quality was assessed using Fastqc QC (v0.5, Babraham). Results showed that the first 16 bases showed minor sequencing bias so these were trimmed from the sequencing reads. After trimming, the average quality score at each base position was greater than 30 (with the majority being closer to 40).

\section{Alignment of Sequence}

Tophat/Bowtie (v1.5.0) was used to align sequences to the mouse genome (assembly NCBI37). Flagstat (v1.0.0) was used to show that at least $74.9 \%$ of pair end reads aligned to the mouse genome.

\section{Determining FPKM}

For each sample, fragment length per kilobase of exon per million fragments mapped (FPKM) values were generated using Cufflinks (v1.3.0). Quartile normalization (removal of the top 25\% of genes from the FPKM denominator) and bias correction (to improve accuracy of transcript abundance estimation) were used. Mouse transcripts were taken from the NCBIM37.59 gene set.

\section{Determining differentially expressed genes}

Differentially expressed genes were determined using Cuffdiff (v0.0.5). Again, quartile normalization and bias correction were used. 


\section{Computational analyses} Singular value decomposition and hierarchical clustering

For each data subset, aligned paired-end reads were filtered to remove any gene that was not expressed in any of the samples. For the 15 samples at 4 and 6 months, filtering yielded 16888 genes. The profile of each gene was centered on the mean of WT samples at 4 months. Hierarchical clustering was performed based on Euclidean Distance between genes across all samples to identify overall similarity. Singular value decomposition (SVD) was used to identify common signals and verify consistency across replicate cohorts. The first SVD component of the 15 samples at 4 and 6 months, which separated the two age cohorts, accounted for $38 \%$ of the global variance. The second component, primarily driven by mutant samples at 4 months, represented $10 \%$ of the variance. For the subset of 8 samples taken at 4 months, the first SVD component separated mutant from WT samples and accounted for $28 \%$ of the variance.

\section{Pathway analyses of differentially expressed genes}

Annotations were generated and overrepresented pathways were identified using DAVID v6.7 (http://david.abcc. ncifcrf.gov/). P values reported in this study were corrected for multiple tests. Pathways were colored using Kyoto Encyclopedia of Genes and Genomes (KEGG - http://www. genome.jp/kegg/tool/map_pathway2.html).
Immunofluorescence, immunohistochemistry and imaging Immunofluorescence

Mice were transcardially perfused with $4 \%$ PFA in $1 \times$ PBS. Brains were dissected and postfixed in 4\% PFA overnight, cryoprotected in $10 \%$ and $30 \%$ sucrose, and embedded in OCT. Frozen sections $(25 \mu \mathrm{m})$ were incubated for $1-2$ nights in the following primary antibodies: mouse antiphosphorylated neurofilament (2 F11; 1:1,000; Dako), rabbit anti-IBA1 (1:500, Wako), rabbit anti-MBP (1:1000; Abcam), rabbit polyclonal GFAP (1:300, Dako); rabbit polyclonal OXT (1:200, Abcam); and goat polyclonal IRS4 (1:200; Everest Biotechnology). With the exception of anti-OXT, the rabbit polyclonal antibodies were diluted in PBTB (1× PBS with $1 \%$ TritonX-100 and 1\% BSA) containing $10 \%$ of normal goat serum and the goat polyclonal antibody was diluted in PBT $(1 \times$ PBS with $1 \%$ TritonX-100) containing $10 \%$ donkey serum. For anti-OXT, the BSA was not included in the dilution buffer. After incubation with the primary antibodies, the brain sections were washed with PBT and incubated in the respective secondary antibodies (goat anti-mouse Alexa Fluor 647 and goat anti-rabbit Alexa Fluor 488, 1:1000 dilution, Invitrogen) for $2 \mathrm{~h}$, washed in PBT, counterstained with DAPI, and mounted with Aqua-PolyMount. For Thio-T staining, brain sections processed for GFAP immunohistochemistry were incubated $10 \mathrm{~min}$ in $1 \%$ Thio- $\mathrm{T}$ (diluted in $\mathrm{dH}_{2} \mathrm{O}$ ), transferred to $0.5 \%$ Acetic acid for $10 \mathrm{~min}$, rinsed in $\mathrm{dH}_{2} \mathrm{O}$ for $5 \mathrm{~min}$ and mounted with Aqua-PolyMount. Thio-T

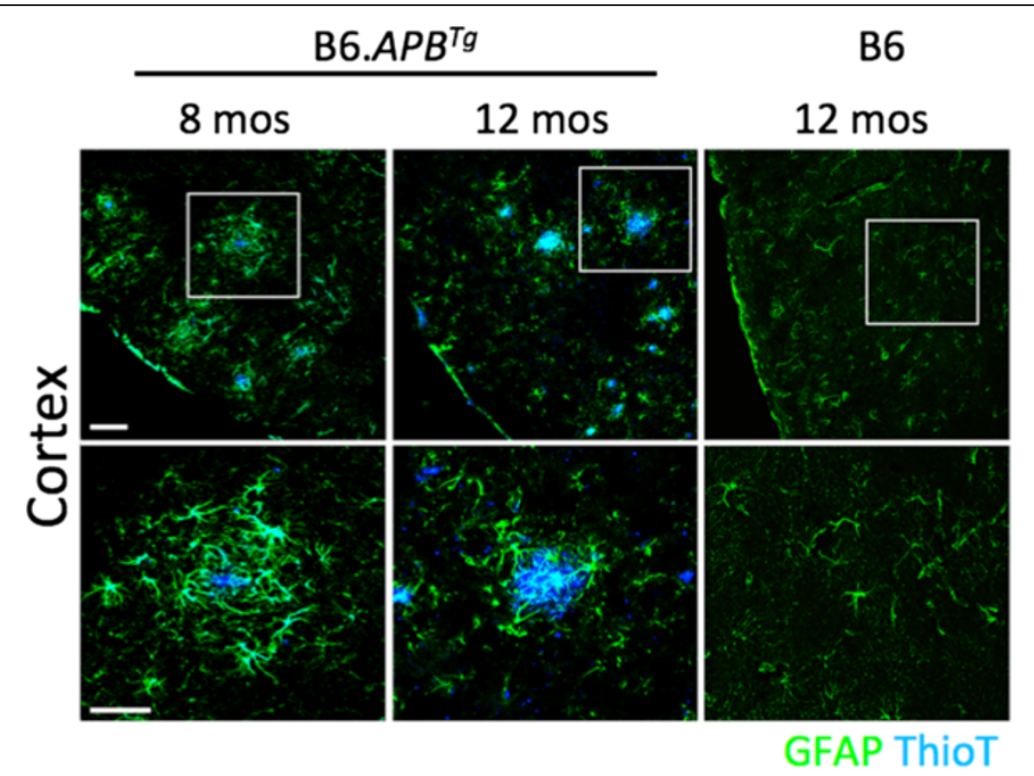

Figure 1 Brain regions of female B6.APB ${ }^{T g}$ mice show amyloid plaques at 8-12 months of age. Brains of female B6.APB ${ }^{T g}$ mice were assessed for plaque deposition from 8-12 months of age. Plaques were visualized using Thioflavin T (Thio T, blue). Plaques were very obvious in the cortex, hippocampus and other brain regions in all mice assessed. Size and number of plaques increased with increasing age. In general, plaques were associated with reactive astrocytes (as determined by glial fibrillary acidic protein (GFAP) staining, green). DAPI was used to identify nuclei. Scale bars; Upper panels $=100 \mu \mathrm{m}$, lower panels $=50 \mu \mathrm{m}$. 
is a dye that binds to beta sheet-rich structures such as amyloid plaques and produces similar results to those obtained with antibodies to $A \beta$ such as $4 \mathrm{G} 10$ and $6 \mathrm{E} 10$ (data not shown).

\section{Imaging}

For each antibody, at least $4 \mathrm{AD}$ and $4 \mathrm{WT}$ sections from multiple brain regions were assessed. Particular attention was given to the cortex, hippocampus and hypothalamus. Imaging and photography was performed on both a Zeiss Axio Imager microscope and a Leica SP5 confocal microscope. Post image processing was performed in Fiji (http://fiji.sc/Fiji).

\section{Results}

\section{$A D$ phenotypes first occur in B6.APB ${ }^{T g}$ mice from 4 months of age}

The main aim of this study was to use transcript profiling to identify molecular changes that impact the onset and very early stages of $\mathrm{AD}$. Therefore, to determine the ideal ages to profile, we assessed B6. $A P B^{T g}$ female mice between 2 and 12 months of age for AD phenotypes including plaque formation, reactive astrogliosis and activation of microglia (Figures 1, 2 and 3).

Previous reports using the B6.APB ${ }^{T g}$ strain show that females develop plaques and other AD-like phenotypes from around 6-8 months of age [2,42-44]. Given the potential for environmental differences to influence onset and progression of $\mathrm{AD}$ in different colonies of mice, we first assessed AD phenotypes in our colony from 8-12 months of age. As expected, mice of all ages within this span showed plaques in multiple brain regions and there was an observable increase in plaque numbers and size with increasing age (Figure 1). Activation of microglia both surrounding plaques and associated with axonal swellings was also observed at these time points (Figure 2). As previously reported, we saw no significant loss of neurons in any brain regions including the cortex and hippocampus at these ages (data not shown). These results indicate that onset and early stages of $\mathrm{AD}$ are occurring in B6.APB ${ }^{T g}$ female mice younger than 8 months old.

Therefore, we assessed AD phenotypes in mice 2-6 months old. At 2 months of age, B6.APB ${ }^{T g}$ female mice were indistinguishable from WT controls. However, by 4 months of age, very small plaques were observed in discrete regions of the brain, particularly in the cortex (Figure 3). Plaques were readily observed in 6 months mice in the cortex and hippocampus. Together these results indicated that profiling B6.APB ${ }^{T g}$ female mice at 4-6 months of age would identify very early molecular changes that may be key drivers and/or important biomarkers of early stages of AD.

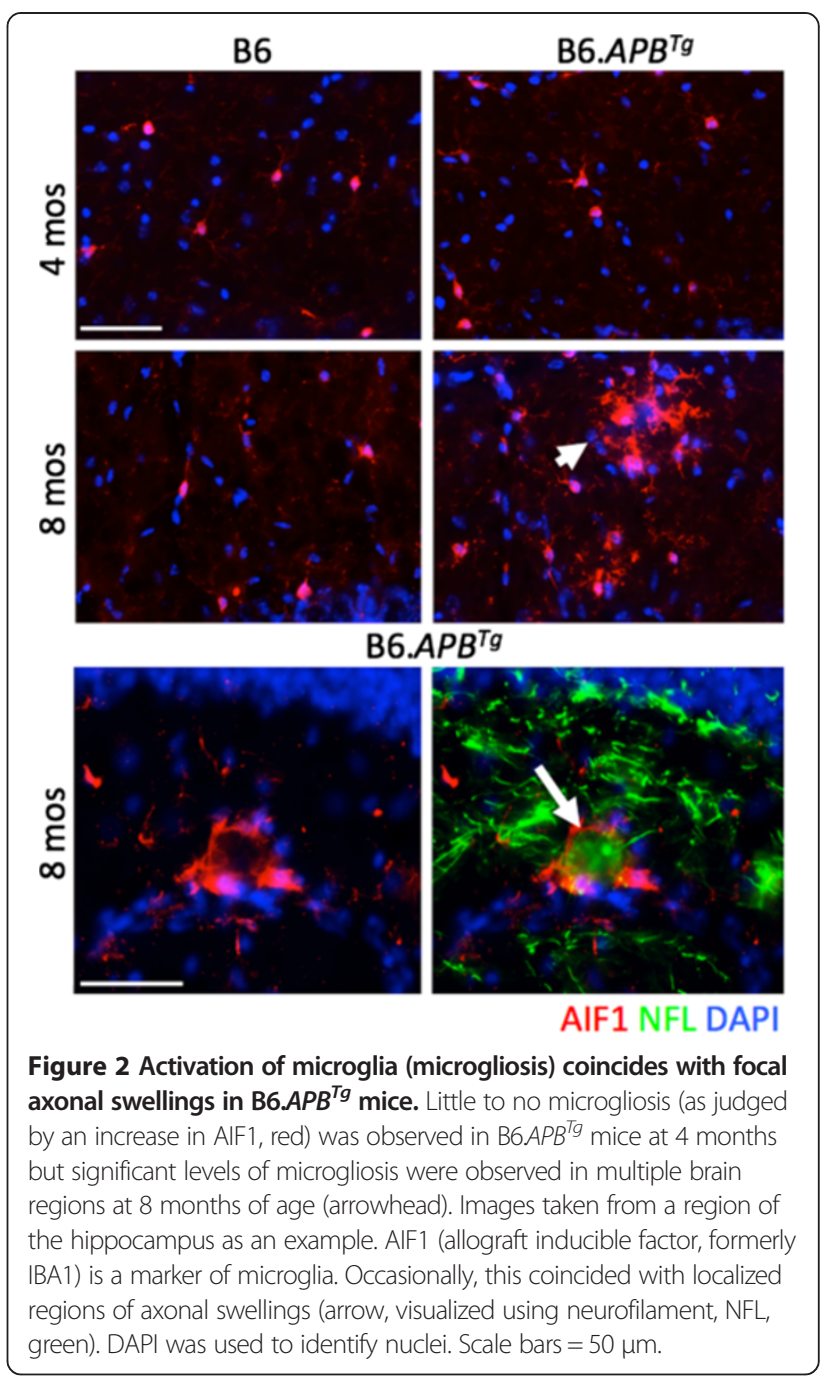

\section{Clustering of transcriptional profiles identifies age is a} major driver of disease onset

To identify early molecular changes in $\mathrm{AD}$, we used RNA-seq to generate transcriptional profiles from 22 female mice (15 AD and 7 WT) from 4, 5, and 6 months of age (see Methods). For each sample, reads were aligned using Tophat [45] and normalized FPKM values were generated for every expressed gene using Cufflinks [46]. To determine the processes driving variation between all 4 and 6 months samples, we used singular value decomposition (SVD). Genes that were not expressed in any samples were removed from the analyses. Strikingly, the largest component of variation was age as the greatest separation was observed between the 4 and 6 months samples (irrespective of genotype). Genotype (i.e. carrying the AD transgenes) was the second major component (Figure 4A). Hierarchical clustering of the samples showed a similar outcome (Figure 4B). Therefore, key age-specific changes are likely to occurring at these ages to drive the onset and early progression of $\mathrm{AD}$ phenotypes. 


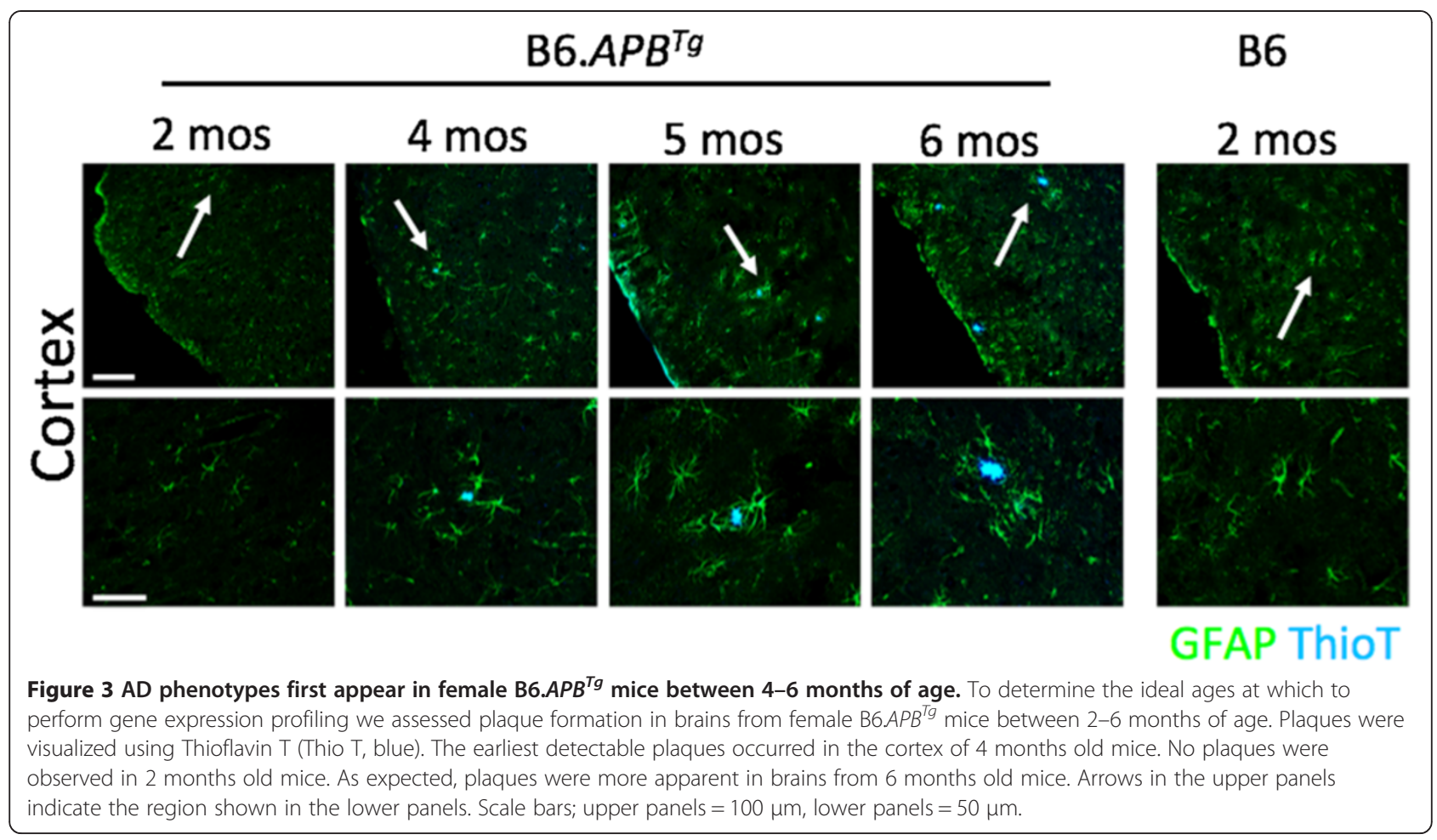

To identify these age-specific changes responsible for the variation between the 4 and 6 months samples, we compared transcript profiles from all 4 months samples (4 AD and $4 \mathrm{WT}, 8$ in total) to profiles from all 6 months samples (4 AD and 3 WT, 7 in total) using Cuffdiff (see Methods). A total of 288 genes were differentially expressed (DE) between the 'all 4 months' and 'all 6 months' groups (Figure 4C and Additional file 1). Similar results were obtained when comparing either the 4 months AD samples to the 6 months AD samples, or the 4 months WT to the 6 months WT samples (data not shown) indicating that these truly are age-specific changes. Pathway analysis revealed that the ribosome and oxidative phosphorylation pathways were over-represented in the $288 \mathrm{DE}$ genes (Figure 4D). These pathways have previously been linked to aging including down-regulation of protein synthesis/mRNA processing and mitochondrial dysfunction [47-54]. Our data imply that perturbations in these pathways are necessary for the onset or early progression of $\mathrm{AD}$ in $\mathrm{B} 6 . A P B^{T g}$ mice. Understanding these age-specific changes is likely important for all forms of Alzheimer's disease, not just the familial form modeled in B6. $A P B^{T g}$ mice.

Disruption to genes normally associated with the hypothalamic-pituitary-adrenal (HPA) axis is an early event in B6.APB ${ }^{\mathrm{Tg}}$ mice

After age, SVD identifies AD genotype as the second greatest component of variation in the 8 samples from the 4 months group (Figure 5A). This is the age at which AD phenotypes were first observed (Figure 3). However, hierarchical clustering identifies that 2 samples (1 AD and $1 \mathrm{WT}$ ) are outliers and likely to decrease the sensitivity to detect true AD-relevant changes (Figure 5B). Therefore, to identify $\mathrm{DE}$ genes important for $\mathrm{AD}$ onset we compared the transcript profiles of the 6 most closely related 4 months samples (3 AD samples vs $3 \mathrm{WT}$ samples) using Cuffdiff. A total of 151 genes were DE between the 4 months $\mathrm{AD}$ and WT groups (Figure $5 \mathrm{C}$ and Additional file 2).

Six of the most downregulated genes comparing the 4 months $\mathrm{AD}$ and WT groups are hormones or hormonerelated. These six genes include growth hormone (Gh, -137.6x), pro-opiomelanocortin (Pomc, -5.5x) and oxytocin $(O x t,-2.8 \times)$. Interestingly, these six genes are commonly associated with the HPA region of the brain and transcript analysis (available through the Allen Brain Atlas) shows expression for Oxt and Pomc only in the hypothalamus. Our data shows similar findings; with the OXT protein almost exclusively localized to the hypothalamic regions surrounding the third ventricle (Figure 6). These HPA-associated genes are involved in a variety of different behaviors including depression, appetite and metabolism. These behaviors have been previously associated with human Alzheimer's disease [55-57]. Our analyses indicate that alterations in these behaviors may occur early in $\mathrm{AD}$ and studying these genes may be important for developing new therapies or as diagnostic criteria for $\mathrm{AD}$. 


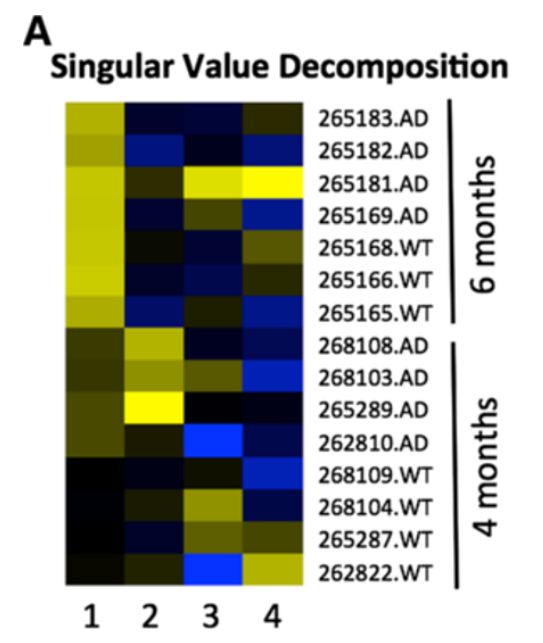

\section{B} Hierarchical clustering

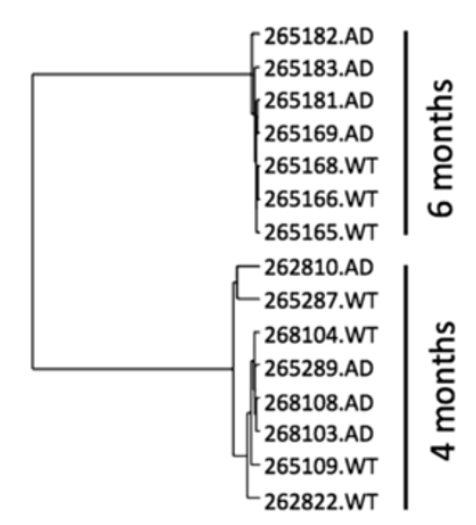

C

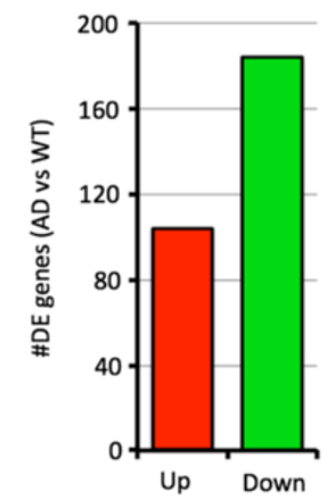

Figure 4 Transcript clustering implies that age-related changes are of primary importance in the development of AD phenotypes. (A) Singular value decomposition of 4 and 6 months samples shows that age (column 1) is the greatest driver of variation between samples. Column 2 shows that genotype is the second greatest driver of variation. (B) This is confirmed using hierarchical clustering. (C) Comparing the 4 months samples with the 6 months samples using Cuffdiff identified 288 genes that were differentially expressed (184 upregulated, 104 down regulated, see Additional file 1: Table S1). (D) Pathway analysis using DAVID showed that members of the ribosome and oxidative phosphorylation pathways (from KEGG) are significantly overrepresented $(P<0.05)$ in the DE gene list.

Clustering of 5 months samples identifies perturbation in the insulin signaling pathway as an important event in AD Our combined approach of histology, transcriptional profiling and computational analyses demonstrates that key events, including age-specific changes, occur between 4 and 6 months of age in B6.APB ${ }^{T g}$ mice. Therefore, we hypothesized that early progression of $\mathrm{AD}$ is likely to be occurring at 5 months as well as at 4 months of age in these mice. To test this, we analyzed the transcriptional profiles from the $7 \mathrm{AD}$ transgene carrying B6.APB ${ }^{T g}$ female mice at 5 months of age. We first determined the similarity of these transcriptional profiles to the 4 and 6 months AD and WT samples using hierarchical clustering. Rather than clustering into a separate 'age-specific' group, the 5 months samples clustered with the 4 and 6 months samples: three of the seven 5 months $\mathrm{AD}$ samples clustered with the 4 months samples and four of the 5 months samples clustered with the 6 months samples (Figure 7A). This shows that indeed crucial changes are occurring independent of absolute age in $\mathrm{AD}$ mice at 5 months of age. These changes may be 'age-specific' due to the 5 months old mice aging at different rates (a widely accepted phenomenon), or 'disease-specific' changes independent of age, or both.

To help answer these questions and to determine the gene expression differences driving the variation between the two groups of 5 months samples (termed stage 1 and stage 2) we used Cuffdiff. A total of 187 genes were differentially expressed comparing the early to late group (Figure $7 \mathrm{~B}$ and Additional file 3). Pathway analysis of the DE genes identified the ribosome pathway and the insulin signaling 

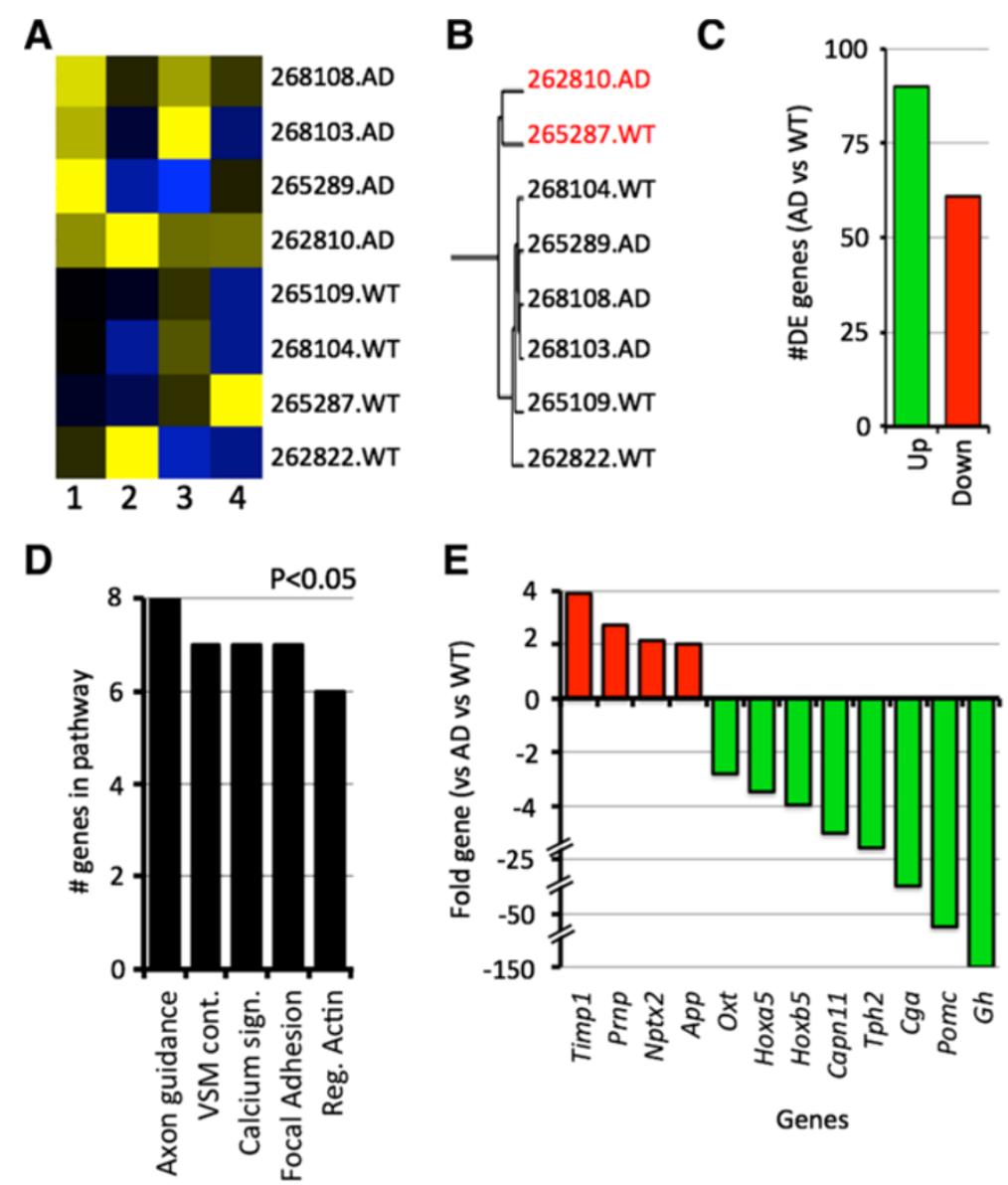

Genes

Figure 5 Transcript clustering identifies that genotype is the major driver of variation in the $\mathbf{4}$ months samples. (A) Singular value decomposition stratifies the 4 months samples into two groups based on genotype. (B). In addition, hierarchical clustering, suggests that two samples (shown in red) are outliers compared to the other samples, and so are not included in comparisons to identify differentially expressed (DE) genes. (C) DE genes were identified by comparing the three 4 months B6.APB ${ }^{\text {Tg }}$ (AD) samples with the three B6 control samples (WT) using Cuffdiff. A total of 151 DE genes were identified (90 upregulated, 61 downregulated, see Additional file 2: Table S2). (D) Pathway analysis identified axon guidance, vascular smooth muscle contraction (VSM cont.) and calcium signaling (Calc sign.) as over-represented pathways $(P<0.05)$. (E) Analysis of the DE genes with the greatest fold changes identified genes commonly associated with the hypothalamus as down regulated including oxytocin $(\mathrm{Oxt})$, glycoprotein hormones, alpha polypeptide (Cga), pro-opiomelanocortin-alpha (Pomc) and growth hormone (Gh).

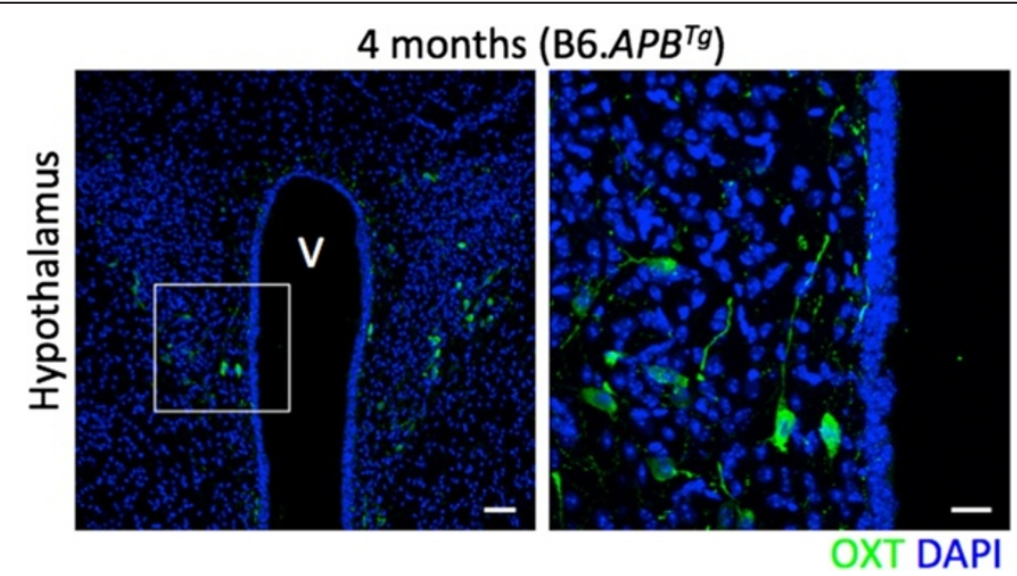

Figure 6 Oxytocin (OXT - green) is localized to neurons in the hypothalamus, particularly surrounding the third ventricle (V). OXT was not observed in all other brain regions assessed (data not shown). Nuclei are visualized with DAPI (blue). Scale bars: left panel $=50 \mu \mathrm{m}$, right panel $=20 \mu \mathrm{m}$. 
B
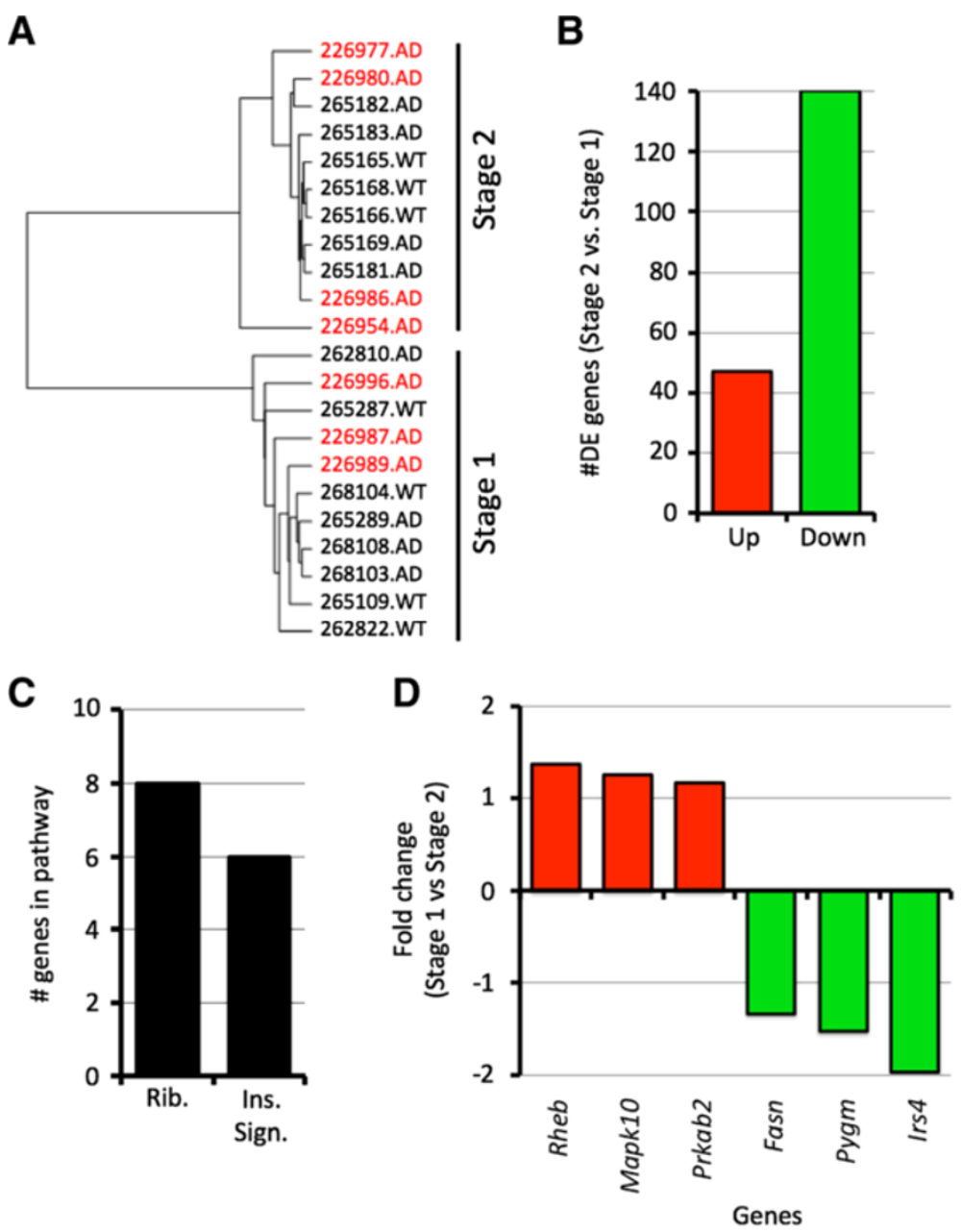

Figure 7 Transcript clustering of 5 months samples identified insulin signaling as a critical pathway activated in early stages of AD. (A) Hierarchical clustering clustered three of the 5 months AD samples with the 4 months samples (now termed Stage 1), and the remaining four with the 6 months samples (now termed Stage 2). The 5 months AD samples are shown in red. (B) The 5 months samples in Stage 1 were compared with the 5 months samples in Stage 2 using Cuffdiff. A total of 187 genes were differentially expressed (47 upregulated, 187 downregulated, see Additional file 3). (C) Pathway analysis showed that both the ribosome (Rib.) and insulin signaling pathway (Ins. Sign.) were overrepresented in the DE genes $(P<0.05)$. (D) Comparing Stage 1 with Stage 2, six genes in the insulin signaling pathway were differentially expressed (3 upregulated, 3 downregulated).

pathway as overrepresented in stage 2 compared to stage 1 (Figure 7C). The ribosome pathway was also overrepresented comparing the 4 to the 6 months data suggesting that differences in physiological aging are driving some of the variation between the chronologically-matched 5 months old samples. Insulin signaling is a novel finding that was only significant in clustering of the 5 months samples. Therefore, it is not clear whether the variation between the 5 months old samples is due in part to the mice physiologically aging at different rates, or diseasespecific changes.

At least six genes in the insulin signaling pathway are differentially expressed in stage 2 compared to stage 1 (Figure 7D). These include three upregulated genes (Prkab2 1.2×, Rheb, 1.3× and Mapk10, 1.3×) and three downregulated genes (Fasn -1.32×, Pygm -1.5× and Irs $4-2.0)$. Insulin receptor substrate 4 (Irs4) is the most downregulated gene in the insulin signaling pathway and is of particular interest as Irs genes have been shown to impact phosphorylation of tau, a crucial step in the generation of neurofibrillary tangles $[58,59]$. Previous studies have localized Irs 4 to specific sets of neurons in the hypothalamus $[60,61]$ and Allen Brain Atlas for mouse shows expression of Irs4 mainly in the hypothalamus and at lower levels in pallidum. Interestingly, the human Allen Brain reports expression of IRS4 in both the hypothalamus and cortex. Our analysis of Irs4 expression agrees with these findings with strongest expression in the hypothalamus and possible low-level expression in the cortex (data not shown). To confirm this 
we localized the IRS4 protein using an anti-IRS4 antibody (see Methods). IRS4 is indeed present in axons of neurons in both the hypothalamus and the cortex (Figure 8). Given our previous findings of early changes to genes associated with the hypothalamus, it is possible that the downregulation of Irs4 (and other insulin signaling genes) is occurring in the HPA region, but it is also possible changes are occurring in the cortex directly and these may be key to the onset/progression of Alzheimer's disease in these mice.

\section{Discussion and conclusions}

Here we report the use of transcript clustering to identify molecular mechanisms contributing to early stages of $\mathrm{AD}$ in mice. This is the first time this approach has been used to assess early events in AD. We show that plaques first appear in the cortex of female B6.APB ${ }^{T g}$ mice around 4 months, and more significantly at 6 months of age. Transcript clustering identified age as the greatest driver of variation in the 4 and 6 months samples, with genotype being the second major driver. Pathway analysis of the genes differentially expressed between the 4 and 6 months samples suggests at least two biological processes are driving these changes namely mRNA processing/protein translation and oxidative phosphorylation. Both of these processes have previously been implicated in age-related changes [47-54]. Although it is unexpected that these aging-linked changes occur so early, it may suggest that subtle aging changes occur in mice as early as 4-6 months. At this age, mice are considered to be equivalent in age to early adulthood in humans (e.g. between 20-40 years of age) an age when mild cognitive impairment (MCI) can occur in some individuals [62].

The earliest AD-relevant changes detected in 4 months $\mathrm{AD}$ mice compared to WT mice were hormone-related and may indicate changes to the HPA axis. Our study is the first to propose that these may be among the earliest changes in $\mathrm{AD}$ and that they may be important indicators of susceptibility to and the onset of AD. Genes expressed by cells in the HPA axis control behaviors such as mood, sleep, and eating and these behaviors are commonly disrupted in $\mathrm{AD}$ patients. For instance, systemic metabolic changes as well as mood changes have been observed in very early phases of $\mathrm{AD}$ and suggest early dysfunction in the hypothalamus [55-57]. Another change seen in AD patients is a behavioral one, affecting mood and depression [63-66]. Oxytocin, often prescribed as a medication to treat depression, is almost exclusively expressed in the hypothalamus [67] and our data shows a downregulation early in B6. $A P B^{T g}$ mice.

It is not clear why the hypothalamus may be more susceptible than other brain regions to early dysfunction in $\mathrm{AD}$ but it may be due to the absence of a traditional blood brain barrier in this region. Instead, vessels surrounding the hypothalamus, particularly the median basal region

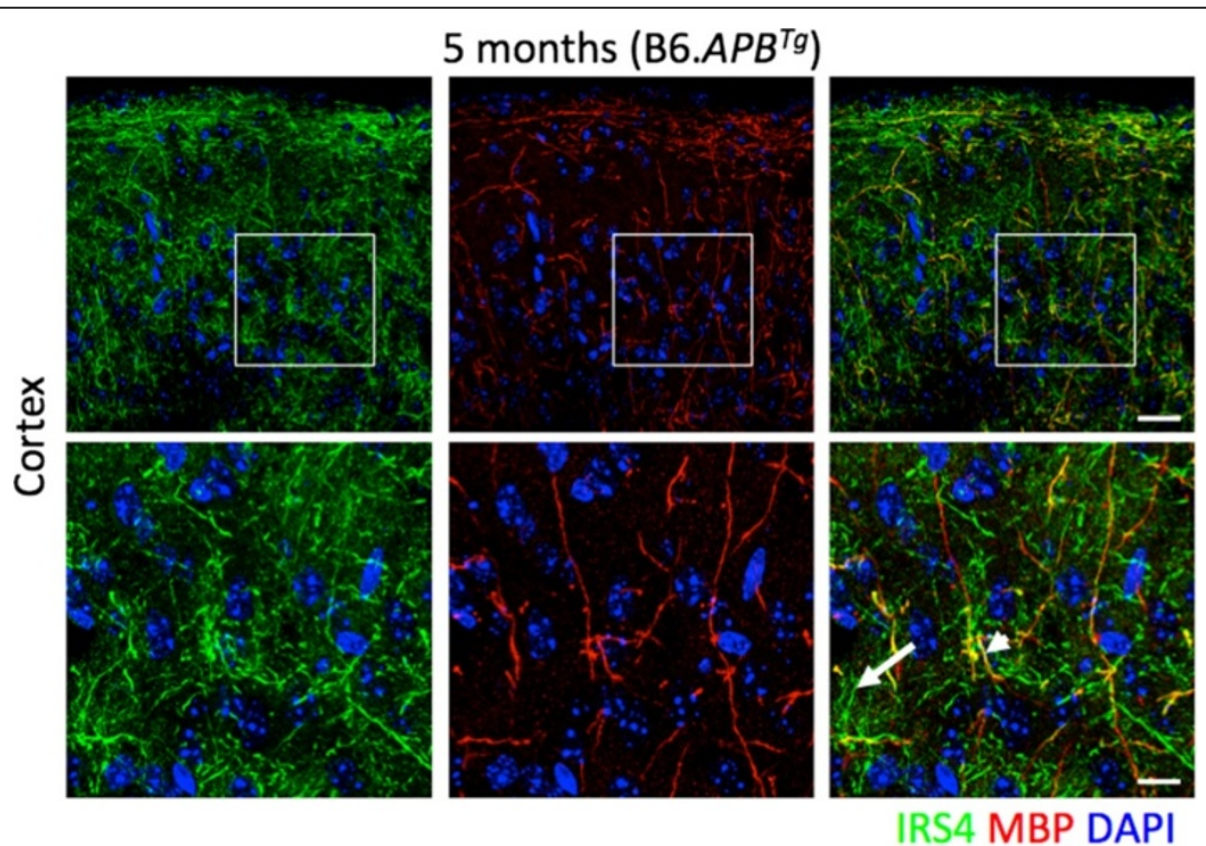

Figure 8 Insulin receptor substrate 4 (IRS4) protein is localized to axons in the cortex. Immnofluorescence was used to determine the location of IRS4 protein. The IRS4 protein (green) is readily detectable in multiple brain regions including the cortex. The majority of the IRS4 protein co-localizes with myelinated axons (as indicated by the significant overlap between IRS4 with myelin basic protein (MBP, red). Colocalization is indicated in yellow (e.g. arrowhead). However, IRS4 is also present in non-myelinated axons (longer arrow, lower right panel). Lower panels are a higher magnification of the boxed regions indicated in the upper panels. Scale bars: upper panels $=25 \mu \mathrm{m}$, lower panels $=10 \mu \mathrm{m}$. 
of the hypothalamus, are fenestrated to allow the easy passage of hormones into the circulation [68-70]. This structure is constitutively leaky and may be particularly susceptible to increases in AD-relevant phenotypes such as amyloid accumulation. Furthermore, vascular dysfunction (such as cerebral hemorrhages or micro-bleeds) may precede the molecular changes identified in our study. Age-related vascular dysfunction has been reported but more detailed studies relating to the role of age-related vasculature dysfunction in $\mathrm{AD}$ are required.

Transcript clustering of the 5 months data identified changes to the insulin signaling pathway including Irs4 as an early event in AD. Insulin signaling is strongly associated with aging and age-related diseases including obesity and diabetes, conditions that have recently been identified as possible risk factors for $\mathrm{AD}$ [71-75]. Irs4 is expressed strongly in the hypothalamus but at lower levels in other brain regions such as the cortex. Therefore, downregulation of Irs 4 likely impacts both the hypothalamus and the cortex. IRS4 is a good candidate for further studies as it is known to function in a number of processes relevant to $\mathrm{AD}$ including interacting with endosomes [76] to control A $\beta$ levels in neurons $[8,77,78]$, or through interactions with Irs2 [79] in the phosphorylation of Tau during the formation of neurofibrillary tangles [58,59]. Although further work is required to elucidate the precise role of IRS4 in AD, our data suggests that understanding the role of IRS4 in AD may lead to potential new therapies for AD.

Our study, using a genetic model relevant to early onset $\mathrm{AD}$, shows that clustering of transcriptional profiling data is a powerful method to identify important early molecular changes at the onset of traditional hallmarks of AD. However, it is widely accepted that these models do not recapitulate all aspects of $\mathrm{AD}$ including hyperphosphorylation of Tau leading to neurofibrillary tangles and neuronal cell loss. This is intriguing given that mutations that disrupt APP processing do cause neurofibrillary tangles and associated neuronal changes in human AD. Given this, our work highlights the need for further investigation of B6.APB ${ }^{T g}$ mice at the onset of plaque formation to better understand the role of insulin signaling and other early molecular events that follow APP misprocessing. Furthermore, our study focuses on a mouse model relevant to early onset $\mathrm{AD}$, which accounts for $<5 \%$ of all cases human of AD. It is not clear whether mechanisms that lead to plaque formation and neurofibrillary tangles in early onset $\mathrm{AD}$ are similar or distinct to those that lead to AD in late-onset AD. Nevertheless, understanding and targeting these early events is likely to provide the greatest potential for developing new treatments for Alzheimer's disease.

\section{Availability of supporting data}

Raw data is being made available through Geo datasets.

\section{Additional files}

Additional file 1: Table S1. Differentially expressed genes comparing 4 months with 6 months samples.

Additional file 2: Table S2. Differentially expressed genes comparing 4 months WT with 4 months AD samples.

Additional file 3: Table S3. Differentially expressed genes comparing Stage 1 with Stage 2 samples.

\section{Competing interests}

The authors declare that they have no competing interests.

\section{Authors' contributions}

GRH designed and implemented the study. HMJ, IS and LCG performed the histological analyses. HMG and GRH performed the RNA-seq data analyses. GWC performed the computational analyses including singular value decomposition and hierarchical clustering. GRH wrote the manuscript and it was critically read and approved by all authors.

\section{Acknowledgements}

This work was supported in part by the Jane B. Cook 1983 Charitable Trust. G.W.C. was supported in part by grant K25 GM079404 from NIGMS. We thank Katherine MacNicoll and Sam Groh for mouse colony maintenance and tissue harvesting and acknowledge the Scientific Services at The Jackson Laboratory including Genome Technologies, Computational Sciences and imaging Sciences. We are grateful to Stephen Sampson for careful reading of the manuscript.

Received: 6 September 2013 Accepted: 14 November 2013

Published: 25 November 2013

\section{References}

1. Bero AW, Yan P, Roh JH, Cirrito JR, Stewart FR, Raichle ME, Lee JM, Holtzman DM: Neuronal activity regulates the regional vulnerability to amyloid-beta deposition. Nat Neurosci 2011, 14(6):750-756.

2. Jankowsky JL, Fadale DJ, Anderson J, Xu GM, Gonzales V, Jenkins NA, Copeland NG, Lee MK, Younkin LH, Wagner SL, et al: Mutant presenilins specifically elevate the levels of the 42 residue beta-amyloid peptide in vivo: evidence for augmentation of a 42-specific gamma secretase. Hum Mol Genet 2004, 13(2):159-170.

3. Braak H, Braak E: Neuropathological stageing of Alzheimer-related changes. Acta Neuropathol 1991, 82(4):239-259.

4. Sisodia SS, Price DL: Role of the beta-amyloid protein in Alzheimer's disease. FASEB journal: official publication of the Federation of American Societies for Experimental Biology 1995, 9(5):366-370.

5. Price DL, Sisodia SS, Gandy SE: Amyloid beta amyloidosis in Alzheimer's disease. Curr Opin Neurol 1995, 8(4):268-274.

6. Baglietto-Vargas D, Moreno-Gonzalez I, Sanchez-Varo R, Jimenez S, Trujillo-Estrada L, Sanchez-Mejias E, Torres M, Romero-Acebal M, Ruano D, Vizuete $M$, et al: Calretinin interneurons are early targets of extracellular amyloid-beta pathology in PS1/AbetaPP Alzheimer mice hippocampus. J Alzheimer's Disease 2010, 21(1):119-132.

7. Adalbert R, Nogradi A, Babetto E, Janeckova L, Walker SA, Kerschensteiner M, Misgeld T, Coleman MP: Severely dystrophic axons at amyloid plaques remain continuous and connected to viable cell bodies. Brain 2009, 132(Pt 2):402-416.

8. Tanzi RE: The synaptic Abeta hypothesis of Alzheimer disease. Nat Neurosci 2005, 8(8):977-979.

9. Sloane PD, Zimmerman S, Suchindran C, Reed P, Wang L, Boustani M, Sudha S: The public health impact of Alzheimer's disease, 2000-2050: potential implication of treatment advances. Annu Rev Publ Health 2002, 23:213-231.

10. Norton S, Matthews F, Brayne C: A commentary on studies presenting projections of the future prevalence of dementia. BMC Public Health 2013, 13(1):1.

11. Extance A: Alzheimer's failure raises questions about disease-modifying strategies. Nat Rev Drug Discov 2010, 9(10):749-751.

12. Karran E, Mercken M, Strooper BD: The amyloid cascade hypothesis for Alzheimer's disease: an appraisal for the development of therapeutics. Nat Rev Drug Discov 2011, 10(9):698-712. 
13. Schor NF: What the halted phase III $\gamma$-secretase inhibitor trial may (or may not) be telling us. Ann Neuro/ 2011, 69(2):237-239.

14. Grundman M, Dibernardo A, Raghavan N, Krams M, Yuen E: A watershed year for Alzheimer's disease research. J Nutr Health Aging 2012, 17(1):51-53.

15. Sperling R, Salloway S, Brooks DJ, Tampieri D, Barakos J, Fox NC, Raskind M, Sabbagh M, Honig LS, Porsteinsson AP, et al: Amyloid-related imaging abnormalities in patients with Alzheimer's disease treated with bapineuzumab: a retrospective analysis. Lancet Neurol 2012, 11(3):241-249.

16. Cowley T, González-Reyes R, Richardson J, Virley D, Upton N, Lynch M: The Age-related gliosis and accompanying deficit in spatial learning are unaffected by dimebon. Neurochem Res 2013, 38(6):1190-1195.

17. Tanzi RE: The genetics of Alzheimer disease. Cold Spring Harbor Perspectives in Medicine 2012, 2(10). doi: 10.1101/cshperspect.a006296.

18. Price $\mathrm{DL}$, Sisodia SS: Mutant genes in familial alzheimer's disease and transgenic models. Annu Rev Neurosci 1998, 21(1):479-505.

19. Rossor MN, Iversen LL, Reynolds GP, Mountjoy CQ, Roth M: Neurochemical characteristics of early and late onset types of Alzheimer's disease. Br Med J 1984, 288(6422):961-964

20. Kamboh Ml: Molecular genetics of late-onset Alzheimer's disease. Ann Hum Genet 2004, 68(4):381-404.

21. Duara R, Lopez-Alberola RF, Barker WW, Loewenstein DA, Zatinsky M, Eisdorfe CE, Weinberg GB: A comparison of familial and sporadic Alzheimer's disease. Neurology 1993, 43(7):1377.

22. Bertram L, Tanzi RE: The genetics of Alzheimer's disease. Progress in molecular biology and translational science 2012, 107:79-100.

23. Kang J, Lemaire H-G, Unterbeck A, Salbaum JM, Masters CL, Grzeschik K-H, Multhaup G, Beyreuther K, Muller-Hill B: The precursor of Alzheimer's disease amyloid A4 protein resembles a cell-surface receptor. Nature 1987, 325(6106):733-736.

24. Tanzi R, Gusella J, Watkins P, Bruns G, St George-Hyslop P, Van Keuren M, Patterson D, Pagan S, Kurnit D, Neve R: Amyloid beta protein gene: cDNA, mRNA distribution, and genetic linkage near the Alzheimer locus. Science 1987, 235(4791):880-884.

25. Tanzi RE, McClatchey Al, Lamperti ED, Villa-Komaroff L, Gusella JF, Neve RL: Protease inhibitor domain encoded by an amyloid protein precursor mRNA associated with Alzheimer's disease. Nature 1988, 331(6156):528-530.

26. Genin E, Hannequin D, Wallon D, Sleegers K, Hiltunen M, Combarros O, Bullido MJ, Engelborghs S, De Deyn P, Berr C, et al: APOE and Alzheimer disease: a major gene with semi-dominant inheritance. Mol Psychiatr 2011, 16(9):903-907.

27. Bullido MJ, Artiga MJ, Recuero M, Sastre I, Garcia MA, Aldudo J, Lendon C, Han SW, Morris JC, Frank A, et al: A polymorphism in the regulatory region of $\mathrm{APOE}$ associated with risk for Alzheimer's dementia. Nat Genet 1998, 18(1):69-71.

28. Pievani M, Galluzzi S, Thompson PM, Rasser PE, Bonetti M, Frisoni GB: APOE4 is associated with greater atrophy of the hippocampal formation in Alzheimer's disease. Neuroimage 2011, 55(3):909-919.

29. Goedert M: Tau protein and the neurofibrillary pathology of Alzheimer's disease. Trends Neurosci 1993, 16(11):460-465.

30. Kidd M: Paired helical filaments in electron microscopy of Alzheimer's Disease. Nature 1963, 197(4863):192-193.

31. Gilley J, Adalbert R, Coleman MP: Modelling early responses to neurodegenerative mutations in mice. Biochem Soc Trans 2011 39(4):933-938.

32. Hardy J, Selkoe DJ: The amyloid hypothesis of Alzheimer's disease: progress and problems on the road to therapeutics. Science 2002, 297(5580):353-356.

33. Ghiso J, Frangione B: Amyloidosis and Alzheimer's disease. Adv Drug Deliv Rev 2002, 54(12):1539-1551.

34. Rodriguez JJ, Olabarria M, Chvatal A, Verkhratsky A: Astroglia in dementia and Alzheimer's disease. Cell Death Differ 2008, 16(3):378-385.

35. Cohen E, Paulsson JF, Blinder P, Burstyn-Cohen T, Du D, Estepa G, Adame A, Pham HM, Holzenberger M, Kelly JW, et al: Reduced IGF-1 signaling delays age-associated proteotoxicity in mice. Cell 2009, 139(6):1157-1169.

36. Wyss-Coray T, Rogers J: Inflammation in alzheimer disease - a brief review of the basic science and clinical literature. Cold Spring Harb Perspect Med 2012, 2(1). doi: 10.1101/cshperspect.a006346.

37. Tuppo EE, Arias HR: The role of inflammation in Alzheimer's disease. Int J Biochem Cell Biol 2005, 37(2):289-305.

38. Akiyama H, Barger S, Barnum S, Bradt B, Bauer J, Cole GM, Cooper NR, Eikelenboom P, Emmerling M, Fiebich BL, et al: Inflammation and Alzheimer's disease. Neurobiol Aging 2000, 21(3):383-421.
39. Howell GR, Macalinao DG, Sousa GL, Walden M, Soto I, Kneeland SC, Barbay JM, King BL, Marchant JK, Hibbs M, et al: Molecular clustering identifies complement and endothelin induction as early events in a mouse model of glaucoma. J Clin Invest 2011, 121(4):1429-1444.

40. Howell GR, Soto I, Zhu X, Ryan M, Macalinao DG, Sousa GL, Caddle LB, MacNicoll KH, Barbay JM, Porciatti $V$, et al: Radiation treatment inhibits monocyte entry into the optic nerve head and prevents neuronal damage in a mouse model of glaucoma. J Clin Invest 2012, 122(4):1246-1261.

41. Howell GR, Walton DO, King BL, Libby RT, John SW: Datgan, a reusable software system for facile interrogation and visualization of complex transcription profiling data. BMC Genom 2011, 12:429.

42. Meyer-Luehmann M, Spires-Jones TL, Prada C, Garcia-Alloza M, de Calignon A, Rozkalne A, Koenigsknecht-Talboo J, Holtzman DM, Bacskai BJ, Hyman BT: Rapid appearance and local toxicity of amyloid-beta plaques in a mouse model of Alzheimer's disease. Nature 2008, 451(7179):720-724.

43. Garcia-Alloza M, Robbins EM, Zhang-Nunes SX, Purcell SM, Betensky RA, Raju S, Prada C, Greenberg SM, Bacskai BJ, Frosch MP: Characterization of amyloid deposition in the APPswe/PS1dE9 mouse model of Alzheimer disease. Neurobiol Dis 2006, 24(3):516-524.

44. Malm TM, livonen H, Goldsteins G, Keksa-Goldsteine V, Ahtoniemi T, Kanninen K, Salminen A, Auriola S, Van Groen T, Tanila H, et al: Pyrrolidine dithiocarbamate activates Akt and improves spatial learning in APP/PS1 mice without affecting beta-amyloid burden. J Neurosci 2007, 27(14):3712-3721.

45. Trapnell C, Pachter L, Salzberg SL: TopHat: discovering splice junctions with RNA-Seq. Bioinformatics 2009, 25(9):1105-1111.

46. Trapnell C, Williams BA, Pertea G, Mortazavi A, Kwan G, van Baren MJ, Salzberg SL, Wold BJ, Pachter L: Transcript assembly and quantification by RNA-Seq reveals unannotated transcripts and isoform switching during cell differentiation. Nat Biotech 2010, 28(5):511-515.

47. Sohal RS, Mockett RJ, Orr WC: Mechanisms of aging: an appraisal of the oxidative stress hypothesis. Free Radic Biol Med 2002, 33(5):575-586

48. Lesnefsky EJ, Hoppel CL: Oxidative phosphorylation and aging. Ageing Res $\operatorname{Rev} 2006,5(4): 402-433$

49. Shigenaga MK, Hagen TM, Ames BN: Oxidative damage and mitochondrial decay in aging. Proc Natl Acad Sci 1994, 91(23):10771-10778.

50. Swerdlow RH, Burns JM, Khan SM: The Alzheimer's disease mitochondrial cascade hypothesis. J Alzheimers Dis 2010, 20:265-279.

51. Rattan SIS: Synthesis, modifications, and turnover of proteins during aging. Exp Gerontol 1996, 31(1-2):33-47.

52. Brewer G: Messenger RNA decay during aging and development Ageing Res Rev 2002, 1(4):607-625

53. Dröge W, Schipper HM: Oxidative stress and aberrant signaling in aging and cognitive decline. Aging Cell 2007, 6(3):361-370.

54. Balaban RS, Nemoto S, Finkel T: Mitochondria, oxidants, and aging Cell 2005, 120(4):483-495.

55. Vidoni ED, Townley RA, Honea RA, Burns JM, Initiative FtAsDN: Alzheimer disease biomarkers are associated with body mass index. Neurology 2011, 77(21):1913-1920.

56. Loskutova N, Honea RA, Brooks WM, Burns JM: Reduced limbic and hypothalamic volumes correlate with bone density in early Alzheimer's disease. J Alzheimers Dis 2010, 20(1):313-322.

57. lacono RP, Sandyk R: Alzheimer's disease and the pivotal role of the hypothalamus and the intrinsic opioid system. Int J Neurosci 1987, 32(3-4):710-714

58. Killick R, Scales G, Leroy K, Causevic M, Hooper C, Irvine EE, Choudhury Al, Drinkwater L, Kerr F, Al-Qassab H, et al: Deletion of Irs2 reduces amyloid deposition and rescues behavioural deficits in APP transgenic mice. Biochem Biophys Res Comm 2009, 386(1):257-262.

59. Schubert M, Brazil DP, Burks DJ, Kushner JA, Ye J, Flint CL, Farhang-Fallah J, Dikkes $P$, Warot $X M$, Rio $C$, et al: Insulin receptor substrate-2 deficiency impairs brain growth and promotes tau phosphorylation. J Neurosci 2003, 23(18):7084-7092.

60. Numan S, Russell DS: Discrete expression of insulin receptor substrate-4 mRNA in adult rat brain. Brain research Molecular brain research 1999, 72(1):97-102.

61. Li JY, Chai B, Zhang W, Wu X, Zhang C, Fritze D, Xia Z, Patterson C, Mulholland MW: Ankyrin repeat and SOCS box containing protein 4 (Asb-4) colocalizes with insulin receptor substrate 4 (IRS4) in the hypothalamic neurons and mediates IRS4 degradation. BMC Neurosci 2011, 12:95.

62. Flurkey KM, Currer J, Harrison DE: Chapter 20 - Mouse Models in Aging Research. In The Mouse in Biomedical Research (Second Edition). Edited by 
James GF, Muriel TD, Fred WQ, Stephen WB, Christian EN, Abigail SL. Burlington: Academic Press; 2007:637-672.

63. Aznar S, Knudsen GM: Depression and Alzheimer's disease: is stress the initiating factor in a common neuropathological cascade? J Alzheimer's Disease 2011, 23(2):177-193.

64. Gracia-Garcia P, De-la-Camara C, Santabarbara J, Lopez-Anton R, Quintanilla MA, Ventura T, Marcos G, Campayo A, Saz P, Lyketsos C, et al: Depression and incident alzheimer disease: the impact of disease severity. Am J Geriatr Psychiatry 2013. doi: 10.1016/j.jagp.2013.02.011.

65. Swaab DF, Bao AM, Lucassen PJ: The stress system in the human brain in depression and neurodegeneration. Ageing Res Rev 2005, 4(2):141-194.

66. Wilson RS, Arnold SE, Schneider JA, Kelly JF, Tang Y, Bennett DA: Chronic psychological distress and risk of Alzheimer's disease in old age. Neuroepidemiology 2006, 27(3):143-153.

67. Burbach JPH, Voorhuis TAM, van Tol HHM, Ivell R: In situ hybridization of oxytocin messenger RNA: Macroscopic distribution and quantitation in rat hypothalamic cell groups. Biochem Biophys Res Commun 1987, 145(1):10-14.

68. Rodriguez EM, Blazquez $\mathrm{JL}$, Guerra M: The design of barriers in the hypothalamus allows the median eminence and the arcuate nucleus to enjoy private milieus: the former opens to the portal blood and the latter to the cerebrospinal fluid. Peptides 2010, 31(4):757-776.

69. Ciofi P, Garret M, Lapirot O, Lafon P, Loyens A, Prévot V, Levine JE: Brain-endocrine interactions: a microvascular route in the mediobasal hypothalamus. Endocrinology 2009, 150(12):5509-5519.

70. Krisch B, Leonhardt $\mathrm{H}$ : The functional and structural border of the neurohemal region of the median eminence. Cell Tissue Res 1978, 192(2):327-339.

71. O'Neill C, Kiely AP, Coakley MF, Manning S, Long-Smith CM: Insulin and IGF-1 signalling: longevity, protein homoeostasis and Alzheimer's disease. Biochem Soc Trans 2012, 40(4):721-727.

72. de la Monte SM: Brain insulin resistance and deficiency as therapeutic targets in Alzheimer's disease. Curr Alzheimer Res 2012, 9(1):35-66.

73. Naderali EK, Ratcliffe SH, Dale MC: Review: obesity and Alzheimer's disease: a link between body weight and cognitive function in old age. Am J Alzheimers Dis Other Demen 2009, 24(6):445-449.

74. Hildreth KL, Van Pelt RE, Schwartz RS: Obesity, insulin resistance, and Alzheimer's disease. Obesity 2012, 20(8):1549-1557.

75. Bartke A: Impact of reduced insulin-like growth factor-1/insulin signaling on aging in mammals: novel findings. Aging Cell 2008, 7(3):285-290.

76. Sano H, Liu SC, Lane WS, Piletz JE, Lienhard GE: Insulin receptor substrate 4 associates with the protein IRAS. J Biol Chem 2002, 277(22):19439-19447.

77. Cataldo AM, Hamilton DJ, Barnett JL, Paskevich PA, Nixon RA: Properties of the endosomal-lysosomal system in the human central nervous system: disturbances mark most neurons in populations at risk to degenerate in Alzheimer's disease. J Neurosci 1996, 16(1):186-199.

78. Cataldo AM, Peterhoff CM, Troncoso JC, Gomez-Isla T, Hyman BT, Nixon RA Endocytic pathway abnormalities precede amyloid beta deposition in sporadic Alzheimer's disease and Down syndrome: differential effects of APOE genotype and presenilin mutations. Am J Pathol 2000, 157(1):277-286.

79. Tsuruzoe K, Emkey R, Kriauciunas KM, Ueki K, Kahn CR: Insulin receptor substrate 3 (IRS-3) and IRS-4 impair IRS-1- and IRS-2-mediated signaling. Mol Cell Biol 2001, 21(1):26-38.

doi:10.1186/1471-2164-14-831

Cite this article as: Jackson et al:: Clustering of transcriptional profiles identifies changes to insulin signaling as an early event in a mouse model of Alzheimer's disease. BMC Genomics 2013 14:831.

\section{Submit your next manuscript to BioMed Central and take full advantage of:}

- Convenient online submission

- Thorough peer review

- No space constraints or color figure charges

- Immediate publication on acceptance

- Inclusion in PubMed, CAS, Scopus and Google Scholar

- Research which is freely available for redistribution

Submit your manuscript at www.biomedcentral.com/submit
Ciomed Central 